\title{
Adsorption of copper ions onto microwave stabilized heavy metal sludge
}

\author{
Ching-Hong Hsieh ${ }^{\text {a }}$, Shang-Lien Lo ${ }^{\mathrm{a}, *}$, Wen-Hui Kuan ${ }^{\mathrm{b}}$, Ching-Lung Chen ${ }^{\mathrm{a}}$ \\ ${ }^{a}$ Research Center for Environmental Pollution Prevention and Control Technology, Graduate Institute of Environmental Engineering, \\ National Taiwan University, 71, Chou-Shan Road, Taipei 106, Taiwan, ROC \\ ${ }^{\mathrm{b}}$ Department of Environmental and Safety Engineering, Ming-Chi University of Technology, No. 84, \\ Gongjhuan Road, Taishan, Taipei Hsien 243, Taiwan, ROC
}

Received 12 July 2005; received in revised form 9 December 2005; accepted 12 December 2005

Available online 27 January 2006

\begin{abstract}
Microwave stabilized heavy metal sludge was used as an adsorbent to remove the copper ions from aqueous solution. The adsorption characteristics of copper on the stabilized-sludge were studied by various models, such as Freundlich and Langmuir isotherm equation. Results show that the $\mathrm{pH}_{\mathrm{zpc}}$ of stabilized-sludge was at 9.2-9.5. Moreover, the adsorption of copper ions onto the stabilized-sludge surface was mainly on account of the heterogeneous surface of the stabilized-sludge. In the dynamic study, the experimental data was fitted to the intraparticle diffusion model, pseudo-first order model and pseudo-second order model. However, the experimental data was only well correlated with pseudo-second order model with the correlation coefficient $>0.995$.

Furthermore, both Freundlich and Langmuir isotherm equations were found to represent the measured adsorption data well. From the Langmuir equation, the adsorption capacity increased from 18 to $28 \mathrm{mg} / \mathrm{g}$ as the temperature rose from 15 to $55^{\circ} \mathrm{C}$, since this adsorption process was an endothermic reaction. After this adsorption process, copper ions can be concentrated on and in a small bead and recovery efficiently.
\end{abstract}

(C) 2005 Elsevier B.V. All rights reserved.

Keywords: Microwave-stabilized sludge; Heavy metal sludge; Copper; Adsorption

\section{Introduction}

Heavy metal sludge produced by industrial wastewater treatment of printed circuit board plants is often regarded as a hazardous material. Copper ions in sludge are easy to leach out, and the concentration of metals often exceeds the legal criteria. Except for the metal ions, the heavy metal sludge also contains several salts: $\mathrm{CaSO}_{4}, \mathrm{CaCO}_{3}, \mathrm{NaCl}, \mathrm{NaHCO}_{3}$ and insoluble metal hydroxide and $\mathrm{M}(\mathrm{OH})_{n}$ [1]. In Taiwan, though copper ion in waste metal sludge is mostly treated with sulfuric acid and recovered by crystallization process, the leaching concentration of copper ions in the residual sludge under TCLP test still cannot meet the legal criterion $(15 \mathrm{mg} / \mathrm{L})$.

For years, microwave technique, offering the advantage of uniform and rapid heating, has been widely applied to the treatment of some environmental materials. These applications included heating and pyrolysis [2,3], extraction and digestion [4-10], synthesis [11-13] and sample preparation [14,15].

\footnotetext{
* Corresponding author. Tel.: +886 223625373; fax: +886223928830.

E-mail address: sllo@ccms.ntu.edu.tw (S.-L. Lo).
}

Moreover, the stabilization and immobilization of metal ions in soil and metal sludge through the microwave treatment are also reported [16-18]. This demonstrates that microwave treatment is quite efficient in inhibiting the leaching of metal ions from soil or sludge. Hence, the treated soil or sludge becomes a stable matrix for application.

For reducing the problems of metal ions in aqueous solution, many low-cost adsorbents have been used efficiently. These adsorbents include agricultural by-products [19-23], sewage sludge, metal hydroxide, soil minerals, etc. [24-27]. The reuse of these cheaper adsorbents for the adsorption of metal ions could achieve the goal of reclamation of solid wastes.

In this study, the adsorption of copper ions onto stabilizedsludge treated by microwave stabilization process was investigated. According to TCLP test, copper concentration in the raw sludge conformed to the legal criterion after the microwave stabilization process. Therefore, the microwave stabilization process-treated sludge was denominated as stabilized-sludge. The objectives of this research were to (1) investigate the chemical composition and surface characteristics of stabilizedsludge, (2) develop the kinetics relationship between copper ions and stabilized-sludge and (3) realize the influences of the 
initial $\mathrm{pH}$ and temperatures on adsorption of $\mathrm{Cu}$ onto stabilizedsludge.

\section{Materials and methods}

\subsection{Sample preparation and characteristics}

Raw heavy metal sludge came from Heavy Metal Sludge Treatment Plant, Tao-Yuan County, Taiwan, and had been handled by acid extraction process. However, according to toxic characteristics leaching procedure (TCLP, method 1311 published by USEPA) copper ion concentrations of the raw sludge, $33.10 \mathrm{mg} / \mathrm{L}$, still exceeded the criteria of waste disposal in Taiwan, $15 \mathrm{mg} / \mathrm{L}$.

In this study, the raw heavy metal sludge was first dried at $105^{\circ} \mathrm{C}$ for $12 \mathrm{~h}$ at least until the moisture was removed and two successive weighting of sludge was maintained at a constant value within $\pm 1 \%$. Then it was crushed with a grinder and sieved till the particle diameter ranged between 100 and 400 mesh $(0.15-0.063 \mathrm{~mm})$. The fine sludge was stored in a $20 \mathrm{~L}$ bucket with a plastic cover. Afterward the raw sludge was treated by microwave stabilization process that was established in previous study [18]. The operation parameters of microwave stabilization process are of power of $600 \mathrm{~W}$, reaction time of $12 \mathrm{~min}$, additive of $0.8 \mathrm{~g}$ Fe powder and liquid $\left(\mathrm{H}_{2} \mathrm{O}\right)$ to solid (sludge) ratio of 1 . The TCLP test results showed that the copper ion of heavy metal sludge was "stabilized" through the microwave stabilization process with the leaching concentration of $1.04 \mathrm{mg} / \mathrm{L}$. Hence, the stabilized-sludge was taken as the adsorbent in later adsorption experiment. Before performing the adsorption experiments, the stabilized-sludge was washed three times with a $0.01 \mathrm{M} \mathrm{KNO}_{3}$ solution at $\mathrm{pH} 7.2$ adjusted by $\mathrm{HNO}_{3}$ and $\mathrm{NaOH}$ to remove debris and alkaline materials on the surface [28]. The washed-sludge was then frozen dried prior to storage.

Stock copper solution was prepared with distilled water and $\mathrm{Cu}\left(\mathrm{NO}_{3}\right)_{2} \cdot 3 \mathrm{H}_{2} \mathrm{O}$ (reagent grade). The solution $\mathrm{pH}$ was adjusted with $0.1 \mathrm{M} \mathrm{HNO}_{3}$ and $0.1 \mathrm{M} \mathrm{NaOH}$. The concentration of metal ions were analyzed by flame atomic adsorption spectrometer (FAAS).

The chemical composition of the raw heavy metal sludge was determined by modified microwave digestion method consulted from previous studies $[5,29]$ with a microwave oven to quantify the metal contents. Samples of $0.1 \mathrm{~g}$ raw heavy metal sludge were well mixed with $\mathrm{HNO}_{3}-\mathrm{HCl}-\mathrm{HF}$ solution $(3 \mathrm{~mL}$ individually) and two-stage programs of the microwave process were carried out. The first stage is $650 \mathrm{~W}$ for $10 \mathrm{~min}$ (final temperature $160{ }^{\circ} \mathrm{C}$ ) and the second stage is $800 \mathrm{~W}$ for $15 \mathrm{~min}$ (final temperature $200^{\circ} \mathrm{C}$ ). After the microwave-assisted digestion process, the mixtures were cooled down to room temperature. The mixtures were also filtered and quantified to $50 \mathrm{~mL}$ before being analyzed. The same procedure was also followed for stabilizedsludge.

Surface charge, $Q(\mathrm{mV})$, of the stabilized-sludge in the aqueous solution was measured at different $\mathrm{pH}$ values by Malvern Zetasizer 3000. Afterward surface change measurements were plotted versus $\mathrm{pH}$.

\subsection{Adsorption kinetics experiment}

In the kinetics experiments, different dosages $(0.08,0.1$, 0.12 and $0.15 \mathrm{~g}$ ) of stabilized-sludge were added to $100 \mathrm{~mL}$ of $30 \mathrm{mg} / \mathrm{L}$ copper solution in $250 \mathrm{~mL}$ flasks. The initial $\mathrm{pH}$ of the copper solution was adjusted at $4 \pm 0.3$ with $\mathrm{NaOH}$ and $\mathrm{HNO}_{3}$. The mixtures were then shaken in a temperature-controlled water bath at $120 \mathrm{rpm}$ and $25 \pm 1{ }^{\circ} \mathrm{C}$. At different desired contact times, the mixtures were taken and filtered using filter paper $(0.5 \mu \mathrm{m})$ made by glass fiber. The remaining copper ion concentrations were then analyzed by FAAS.

Furthermore, several adsorption models have been applied to depicting the adsorption mechanism between adsorbent and adsorbate, such as the intra-particle diffusion model, pseudofirst-order kinetics model and pseudo-second order kinetics model. Each was discussed as follows.

Intra-particle diffusion model of Weber and Morris [33] is expressed as

$Q_{t}=K_{\mathrm{i}} T^{1 / 2}$.

The pseudo-first-order kinetic model of Lagergen [34] is

$\frac{\mathrm{d} Q}{\mathrm{~d} t}=K_{1}\left(Q_{\mathrm{e}}-Q\right)$.

After definite integration by applying the initial condition $Q_{t}=0$ at $T=0$ and $Q=Q_{t}$ at $T=t$, it can also be expressed as

$\log \left(Q_{\mathrm{e}}-Q_{t}\right)=\log Q_{\mathrm{e}}-\frac{K_{1} T}{2.303}$.

The pseudo-second order presented by Ho and McKay [36] is

$\frac{T}{Q_{t}}=\frac{1}{K_{2} Q_{\mathrm{e}}^{2}}+\frac{T}{Q_{\mathrm{e}}}$,

where $Q_{t}$ and $Q_{\mathrm{e}}$ represent the amounts of solute adsorbate per unit adsorbent $(\mathrm{mg} / \mathrm{g})$ at any time and at equilibrium, respectively. Furthermore, $K_{\mathrm{i}}$ is the intraparticle diffusion rate constant $\left(\mathrm{mg} / \mathrm{g} \mathrm{min}{ }^{1 / 2}\right)$ and $K_{1}(1 / \mathrm{min})$ and $K_{2}(\mathrm{~g} / \mathrm{mg} / \mathrm{min})$ are the rate constants of pseudo-first order model and pseudo-second order model, respectively. In addition, $h=K_{2} Q_{\mathrm{e}}^{2}$ is the initial adsorption rate.

\subsection{Effect of the initial $p H$}

The effect of initial $\mathrm{pH}$ of the copper ion solution on adsorption was determined over a range of $\mathrm{pH}$ value $3-8$. This experiment was performed with $0.1 \mathrm{~g}$ stabilized-sludge and $100 \mathrm{~mL}$ of $30 \mathrm{mg} / \mathrm{L}$ copper solution. The mixtures were shaken in the temperature-controlled water bath at $120 \mathrm{rpm}$ and $25 \pm 1{ }^{\circ} \mathrm{C}$ until reaching equilibrium and the final $\mathrm{pH}$ and copper concentration of the solution were detected.

\subsection{Isotherm study}

Isotherm study of copper ions adsorbed onto the stabilizedsludge was carried out at different adsorbent dosages. The amounts of adsorbent were ranged from 0.08 to $0.3 \mathrm{~g}$ with 
$100 \mathrm{~mL}$ of $30 \mathrm{mg} / \mathrm{L}$ copper solution. The initial $\mathrm{pH}$ and temperature of the copper solution were $4 \pm 0.3$ and $25 \pm 1{ }^{\circ} \mathrm{C}$, respectively. The mixtures were shaken in $250 \mathrm{~mL}$ flasks at $120 \mathrm{rpm}$ until the equilibrium time was reached. The equilibrium copper concentrations, $C_{\mathrm{e}}(\mathrm{mg} / \mathrm{L})$, were analyzed and the amounts of copper adsorbed per gram of stabilized-sludge, $Q_{\mathrm{e}}(\mathrm{mg} / \mathrm{g})$, were calculated. Similar individual isotherm experiments were also conducted at 15, 35, 45 and 55 .

In the course of studying the adsorption isotherm of copper ions onto stabilized-sludge surface, the experimental data was fitted to the Freundlich and Langmuir isotherm equations.

The Freundlich sorption isotherm [37] is used in the linear form as

$\log Q_{\mathrm{e}}=\log k_{\mathrm{F}}+\frac{1}{n \log C_{\mathrm{e}}}$,

where $K_{\mathrm{F}}(\mathrm{mg} / \mathrm{g})$ and $n(\mathrm{~g} / \mathrm{L})$ are the Freundlich constants, which are the adsorption capacity of the adsorbent and the symptom of the favorability of the adsorption process, respectively [35].

Moreover, the Langmuir sorption isotherm [38] has been widely applied to many adsorption processes and systems. The basic assumption of Langmuir adsorption is the monolayer adsorption on the adsorbent surface. It means no more adsorption of ions would occur at a non-active site, since the site was occupied by one ion. The Langmuir adsorption isotherm can be expressed as

$\frac{C_{\mathrm{e}}}{Q_{\mathrm{e}}}=\frac{1}{b Q_{0}}+\frac{C_{\mathrm{e}}}{Q_{0}}$,

where $b$ and $Q_{0}$ are the sorption equilibrium constant, which are the adsorption energy $(\mathrm{L} / \mathrm{g})$ and adsorption capacity $(\mathrm{mg} / \mathrm{g})$, respectively.

\section{Results and discussions}

\subsection{Characteristics of raw heavy metal sludge and stabilized-sludge}

Microwave-assisted digestion was performed for the analysis of chemical compositions of raw heavy metal sludge and stabilized-sludge. As listed in Table 1, the major elements of raw heavy metal sludge and stabilized-sludge were $\mathrm{Ca}, \mathrm{Si}, \mathrm{Fe}$, $\mathrm{Cu}$ and $\mathrm{Al}$ in decreasing sequence. The large amounts of $\mathrm{Ca}, \mathrm{Fe}$ and Al may be attributed to the usage of lime, ferrous sulfate and poly-aluminum chloride, respectively, in wastewater treatment while the $\mathrm{Cu}$ and $\mathrm{Si}$ came from the process of printed circuit board treatment.

Fig. 1 illustrated the variation of surface charge of stabilizedsludge at different $\mathrm{pH}$ values. From the plot, the values of zeta potential were all below $0 \mathrm{mV}$ in the studying $\mathrm{pH}$ range and it meant the negative charge was established on the surface of stabilized-sludge at the adsorption process. The negative charge of the surface may attribute to the high adsorption capacity of cationic ions by electrostatic attraction. Further, the $\mathrm{pH}_{\mathrm{zpc}}$ of stabilized-sludge were much smaller than that of sewage sludge [25], for the existence of metal oxide and sulfide oxide resulted
Table 1

Chemical composition of raw heavy metal sludge and stabilized-sludge

\begin{tabular}{lll}
\hline Element & Proportion $(\mathrm{mg} / \mathrm{g})$ & \\
\cline { 2 - 3 } & Raw sludge & Stabilized-sludge \\
\hline $\mathrm{Ag}$ & 0.15 & N.D. \\
$\mathrm{Al}$ & 12.24 & 3.47 \\
$\mathrm{Ba}$ & 0.92 & N.D. \\
$\mathrm{Ca}$ & 121.33 & 106.63 \\
$\mathrm{Cd}$ & $\mathrm{N} . \mathrm{D}$. & N.D. \\
$\mathrm{Co}$ & 0.11 & $\mathrm{~N} . \mathrm{D}$. \\
$\mathrm{Cr}$ & 0.39 & 1.28 \\
$\mathrm{Cu}$ & 13.07 & 14.2 \\
$\mathrm{Fe}$ & 17.64 & 42.09 \\
$\mathrm{Ga}$ & 0.06 & $\mathrm{~N} . \mathrm{D}$. \\
$\mathrm{K}$ & 2.49 & 1.84 \\
$\mathrm{Mg}$ & 1.89 & 0.84 \\
$\mathrm{Mn}$ & 0.27 & N.D. \\
$\mathrm{Ni}$ & 1.36 & 0.7 \\
$\mathrm{~Pb}$ & 2.27 & N.D. \\
$\mathrm{Si}$ & 65.63 & 67.85 \\
$\mathrm{Zn}$ & 1.08 & 1.62 \\
\hline
\end{tabular}

D.L. (detection limit $)=0.1 \mathrm{mg} / \mathrm{L}(0.025 \mathrm{mg} / \mathrm{g})$ and N.D. means the concentration of metal ion is below detection limit.

from sulfuric acid extraction process and microwave stabilization process of raw sludge. On the contrary, results reported in the researches $[30,31]$ indicated different phenomenon of adsorption of metal ions onto solid phase, goethite and $\mathrm{Fe}(\mathrm{OH})_{3}$. In those studies, appreciable adsorption of cationic ions was at a $\mathrm{pH}$ value below the $\mathrm{pH}_{\mathrm{zpc}}$, even if the surface charge of the adsorbents was mostly positive. Hence, the difference between the stabilized-sludge and other solid adsorbent mentioned above on adsorption may result from the existence of other functional groups on other solid adsorbent.

Moreover, in Fig. 1, the surface charge declined steeply at the $\mathrm{pH}$ ranges of 2-4 and 8-10, but maintained around $-25 \mathrm{mV}$ at the $\mathrm{pH}$ of $4-8$, the $\mathrm{pH}$ interval in which the whole adsorption proceeded.

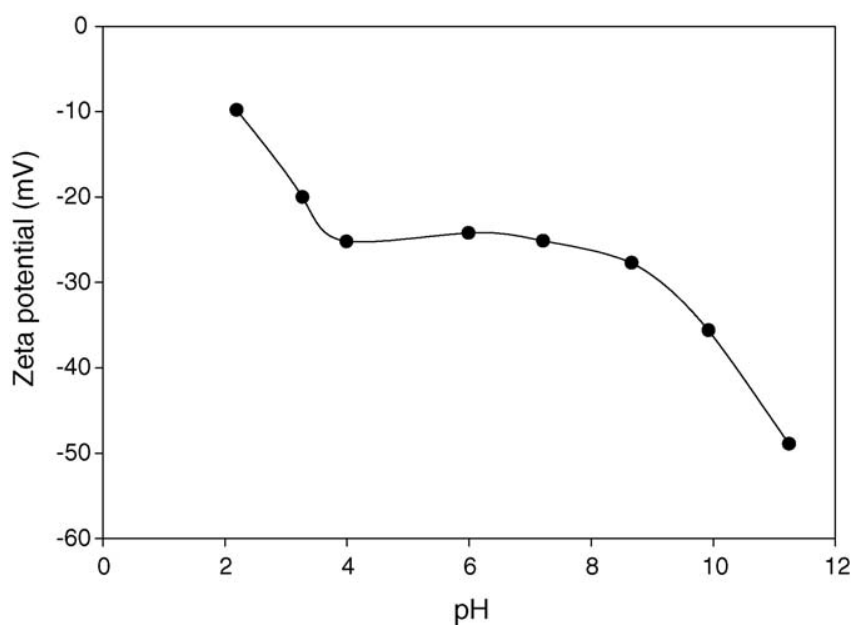

Fig. 1. Variation of surface charge of stabilized heavy metal sludge with system $\mathrm{pH}$. 


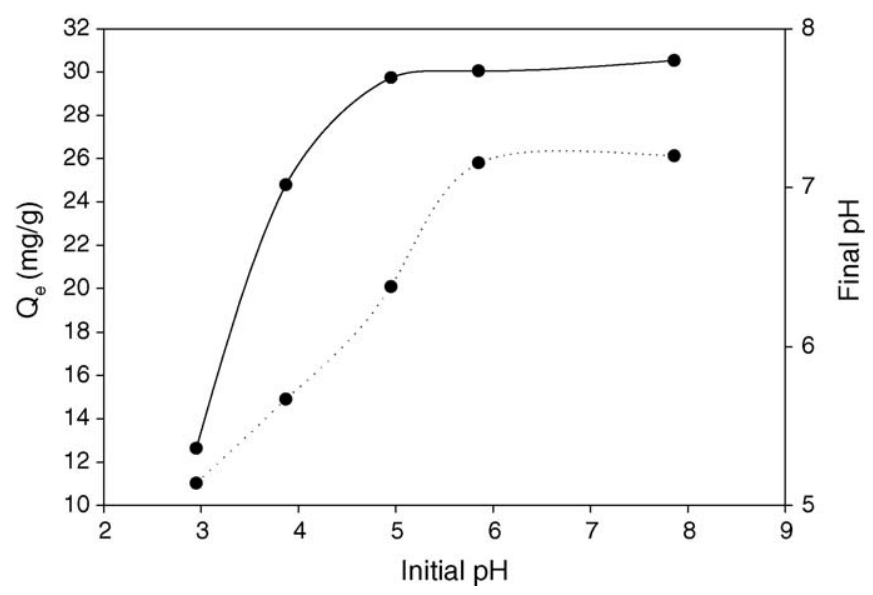

Fig. 2. The effect of initial $\mathrm{pH}$ on the adsorption of $\mathrm{Cu}(\mathrm{II})$ onto stabilized heavy metal sludge. ( . .) Initial pH vs. final pH. (一) Initial pH vs. $Q_{\mathrm{e}}$.

\subsection{Effect of the initial $p H$}

In general, the $\mathrm{pH}$ values affect the species of heavy metals in the aqueous solutions, and the removal of heavy metals increases as the $\mathrm{pH}$ value rises. The $\mathrm{pH}$ value herein ranged from 3 to 8 , and the surface charge of the stabilized-sludge also changed. From the calculation of solubility products $\left(K_{\mathrm{sp}}\right)$, the formation of $\mathrm{Cu}(\mathrm{OH})_{2}$, the precipitating form, of $30 \mathrm{mg} / \mathrm{L}$ copper solution occurred as the $\mathrm{pH}$ value is beyond 6 [32]. As depicted in Fig. 2, the final $\mathrm{pH}$ was over 6 while the initial $\mathrm{pH}$ was above 5. Furthermore, the precipitation formed at $\mathrm{pH}$ 6, with the $Q_{\mathrm{e}}$ at the value of $29.7 \mathrm{mg} / \mathrm{g}$ ( $99 \%$ removal). On the other hand, the $Q_{\mathrm{e}}$ was around $23 \mathrm{mg} / \mathrm{g}$ when the final $\mathrm{pH}$ was 5.6 (initial $\mathrm{pH}$ at 4). This means that the decrease of copper ions in the solution ions does not only attribute to the formation of $\mathrm{Cu}(\mathrm{OH})_{2}$, but also the adsorption of copper ions on the stabilized-sludge surface at the studied $\mathrm{pH}$ range. However, at lower initial $\mathrm{pH}$ values, below 4 , the influence of adsorption is responsible for the reducing of copper ions in the solution.

Also note that the final $\mathrm{pH}$ maintained at a constant of $\mathrm{pH} 7.2$ as the initial $\mathrm{pH}$ was above 6 , which played the role of buffer in this system. This suggests that the process is a suitable application on heavy metals removal because of its neutral and clean effluent.

\subsection{Adsorption kinetics}

Fig. 3 shows the relationship between contacting time and $Q_{t}$, the amount of solute adsorbed per unit adsorbent at any time. The curve rose steeply within the first $5 \mathrm{~min}$, and $Q_{t}$ reached a constant at the 60 min mark. Furthermore, from the preliminary study, a 12-h equilibrium experiment was performed. The equilibrium concentration of copper ions in this adsorption study did not vary obviously from $90 \mathrm{~min}$ to $12 \mathrm{~h}$. Consequently, the equilibrium time of later adsorption experiments was therefore determined at the 90 min mark.

The relationships of $Q_{t}$ versus $T^{1 / 2}$ and $\log \left(Q_{\mathrm{e}}-Q_{t}\right)$ versus $T$ for the intraparticle diffusion model and pseudo-first-order model expressed in Eqs. (1) and (3) of the adsorption of cop-

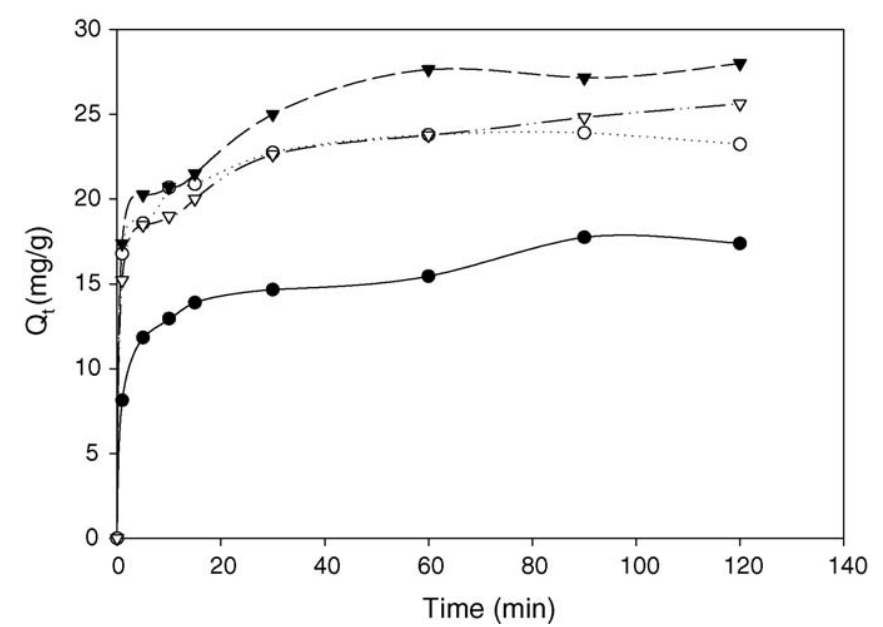

Fig. 3. The adsorption kinetics of $\mathrm{Cu}(\mathrm{II})$ ions onto stabilized heavy metal sludge $(\mathrm{L} / \mathrm{S}=\mathrm{L} / \mathrm{g}) .(\bullet) 0.08 \mathrm{~g},(\bigcirc) 0.1 \mathrm{~g},(\nabla) 0.12 \mathrm{~g},(\mathbf{\nabla}) 0.15 \mathrm{~g}$.

per ions onto stabilized-sludge were plotted. From the linear regression analysis, the $R^{2}$ value was 0.4983 for the former and 0.4942 for the latter for the initial concentration of $30 \mathrm{mg} / \mathrm{L}$ at $25^{\circ} \mathrm{C}$. These relationships were not illustrated herein owing to the lower correlation coefficient.

The relationship of $T / Q_{t}$ versus $T$ for the pseudo-second order kinetic model in Eq. (4) is demonstrated in Fig. 4. The result of linear regression analysis of this curve showed that the correlation coefficient $R^{2}$ of the pseudo-second order model was greater than 0.995 at the equilibrium time of $120 \mathrm{~min}$. This large agreement between experiment data and the pseudo-second-order model implied that, compared with the lower correlation coefficients of the first two models, the pseudo-second order kinetic model seemed to be more suitable for simulating the adsorption of copper onto stabilized-sludge surface. Moreover, for it also could be regarded as an activated sorption mechanism for chemical reaction was important and significant in the rate-controlling step [36].

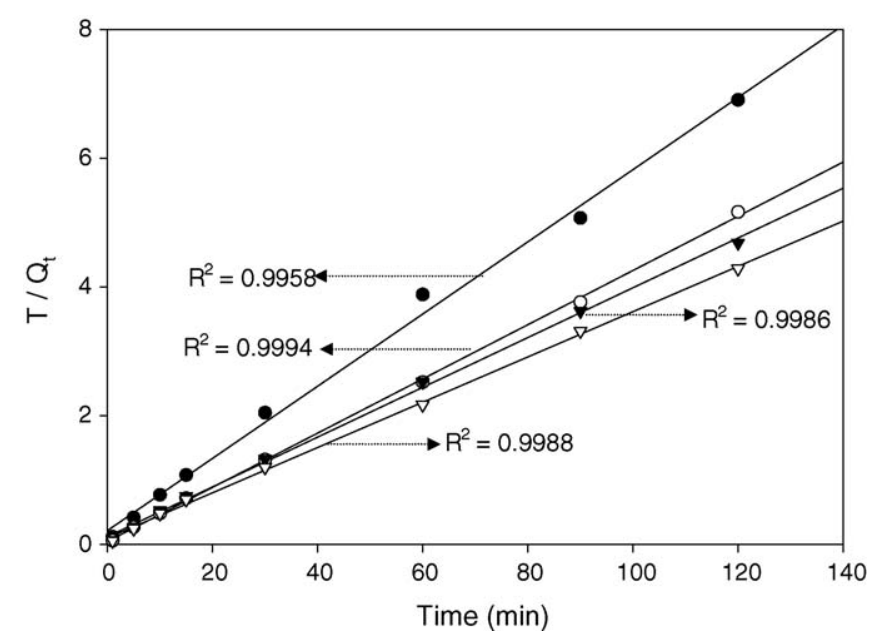

Fig. 4. Pseudo-second-order kinetics of $\mathrm{Cu}(\mathrm{II})$ ions absorption onto stabilized heavy metal sludge at $25^{\circ} \mathrm{C}$ and initial $\mathrm{pH} 4 \pm 0.3$. (৩) $0.08 \mathrm{~g},(\bigcirc) 0.1 \mathrm{~g},(\nabla)$ $0.12 \mathrm{~g},(\boldsymbol{\nabla}) 0.15 \mathrm{~g}$. 
Table 2

The calculated Freundlich and Langmuir constants and correlation coefficients at $\mathrm{pH} 4 \pm 0.3$ and varying temperatures

\begin{tabular}{|c|c|c|c|c|c|c|}
\hline \multirow[t]{2}{*}{ Temperature $\left({ }^{\circ} \mathrm{C}\right)$} & \multicolumn{3}{|c|}{ Freundlich } & \multicolumn{3}{|c|}{ Langmuir } \\
\hline & $n(\mathrm{~g} / \mathrm{L})$ & $K_{\mathrm{F}}(\mathrm{mg} / \mathrm{g})$ & $R^{2}$ & $b(\mathrm{~L} / \mathrm{g})$ & $Q_{0}(\mathrm{mg} / \mathrm{g})$ & $R^{2}$ \\
\hline 15 & 14.86 & 15.22 & 0.9503 & 19.32 & 17.58 & 0.9993 \\
\hline 35 & 12.82 & 20.06 & 0.9868 & 19.62 & 23.53 & 0.9998 \\
\hline 45 & 10.81 & 22.58 & 0.9624 & 55.14 & 25.91 & 0.9994 \\
\hline 55 & 9.11 & 24.86 & 0.9762 & 50.77 & 28.25 & 0.9990 \\
\hline
\end{tabular}

Table 3

Langmuir coefficients and thermodynamic parameters

\begin{tabular}{|c|c|c|c|c|c|}
\hline Temperature $\left({ }^{\circ} \mathrm{C}\right)$ & \multicolumn{2}{|c|}{ Langmuir } & \multicolumn{3}{|c|}{ Thermodynamic parameters } \\
\hline 15 & 17.18 & 83.1 & -2.53 & 5.49 & 27.91 \\
\hline 35 & 21.19 & 157.3 & -3.09 & & \\
\hline 45 & 22.08 & 226.5 & -3.43 & & \\
\hline 55 & 22.52 & 261.1 & -3.63 & & \\
\hline
\end{tabular}

\subsection{Adsorption isotherm}

The adsorption isotherm study is basically essential when discussing an adsorption system. The data of adsorption isotherm for copper ions onto the stabilized-sludge at a constant temperature of $25^{\circ} \mathrm{C}$ and initial concentration of $30 \mathrm{mg} / \mathrm{L}$ was listed in Table 2. It is also interpreted that the complete adsorption could not be reached at that situation for the $Q_{0}$ behind $30 \mathrm{mg} / \mathrm{g}$.

The $K_{\mathrm{F}}$ and $n$ of Freundlich adsorption isotherm were determined from the plot of $L_{n} Q_{\mathrm{e}}$ (natural logarithm $Q_{\mathrm{e}}$ ) versus $L_{n} C_{\mathrm{e}}$ (natural logarithm $C_{\mathrm{e}}$ ) and $Q_{0}$ and $b$ of Langmuir adsorption isotherm can be calculated by the slope and intercept of $C_{\mathrm{e}} / Q_{\mathrm{e}}$ versus $C_{\mathrm{e}}$ indicated which were listed in Table 2 . The Langmuir adsorption capacity $\left(Q_{0}\right)$ was $22.57 \mathrm{mg} / \mathrm{g}$ at $25^{\circ} \mathrm{C}$, which was greater than many other solid wastes, such as tree fern, sewage sludge and herbaceous peat with the adsorption capacity of 10.6 , $3.2-4.1$ and $4.84 \mathrm{mg} / \mathrm{g}$, respectively $[19,25,35]$. Furthermore, as the system temperature rose, the adsorption capacity $\left(Q_{0}\right)$ and $b$ rose to about $17.58,22.57,23.53,25.91$ and $28.25 \mathrm{mg} / \mathrm{g}$ and $19.32,19.47,19.62,55.14$ and $50.77 \mathrm{~L} / \mathrm{g}$, respectively. These results imply that the adsorption capacity and intensity of copper ions onto stabilized-sludge were enhanced at higher temperatures, indicating clearly that that equilibrium of adsorption is temperature-dependent. This effect may be due to the fact that at higher temperatures, an increase in movement of the solute to adsorbent [39]. It also can be explained by the fact that the total energy of sorbate was increased with increasing temperature. Similar situations were displayed in other studies [19,26].

The effect of temperature also could be studied by some thermodynamic parameters, such as Gibbs free energy $\left(\Delta G^{\circ}\right)$, enthalpy $\left(\Delta H^{\circ}\right)$ and entropy $\left(\Delta S^{\circ}\right)$ determined with the following equations [24].

$\Delta G^{\circ}=-R T \ln \left(K_{\mathrm{L}}\right)$, $\ln \left(K_{\mathrm{L}}\right)=\frac{\Delta S^{\circ}}{R}-\frac{\Delta H^{\circ}}{R T}$,

where $R$ is the universal gas constant $(1.987 \mathrm{cal} / \mathrm{mol} / \mathrm{K}), T$ is the temperature in Kelvin $(\mathrm{K})$ and $K_{\mathrm{L}}$ is the Langmuir coefficient calculated from the following equation

$Q_{\mathrm{e}}=\frac{a K_{\mathrm{L}} C_{\mathrm{e}}}{1+K_{\mathrm{L}} C_{\mathrm{e}}}$.

The Langmuir coefficients, $a(\mathrm{mg} / \mathrm{g})$ and $K_{\mathrm{L}}(\mathrm{L} / \mathrm{mg})$ can be obtained from the slope and intercept of $1 / Q_{\mathrm{e}}$ versus $1 / C_{\mathrm{e}}$ and $\Delta H^{\circ}$ and $\Delta S^{\circ}$ were determined from the slope and intercept of van't Hoff plots of $\ln K_{\mathrm{L}}$ versus $1 / T$ as listed in Table 3 . The negative values of $\Delta G^{\circ}$ at $15,25,35,45$ and $55^{\circ} \mathrm{C}$ represent that the adsorption of copper ions onto stabilized-sludge is a spontaneous reaction. The positive value of $\Delta H^{\circ}, 5.49 \mathrm{~kJ} / \mathrm{mol}$, indicates that the adsorption of copper/stabilized-sludge system belongs to endothermic reaction, which is similar to the result of Langmuir isotherm study in this research. Furthermore, depending to the positive and high value of entropy $\left(\Delta S^{\circ}\right), 27.91 \mathrm{~J} / \mathrm{mol} / \mathrm{K}$, a higher randomness tendency between the interface of solid and aqueous phase exists in the process of adsorption. For the characters of spontaneous reaction, endothermic reaction and high randomness, the adsorption of copper ions onto stabilizedsludge may be enhanced at higher temperature.

\section{Conclusion}

The adsorption of copper ions onto stabilized-sludge was studied and leads to the following conclusions:

1. The surface charge of stabilized-sludge was whole negative at the $\mathrm{pH}$ range of $2-11$, indicating the high adsorption capacity and affinity of metal ions onto stabilized-sludge. 
2. The removal of copper ions increased as the initial $\mathrm{pH}$ rose, and the final $\mathrm{pH}$ maintained at a constant of $\mathrm{pH} 7.2$ while the initial $\mathrm{pH}$ is from 6 to 8 .

3. In the kinetic study, the adsorption of copper ions onto adsorbent was fitted to three kinetic models but only the pseudosecond order model was with great correlation coefficient $\left(R^{2}=0.994\right)$. This result shows the adsorption of copper ions onto stabilized-sludge to be an activated adsorption mechanism.

4. The experimental data was also analyzed by the Freundlich and Langmuir adsorption isotherm equations and the correlation coefficient of the Langmuir equation was better than the coefficient for the Freundlich equation.

5. In the isotherm experiment, both the $Q_{0}$ and $b$ increased as the temperature rose from 15 to $55^{\circ} \mathrm{C}$. This implies that the adsorption of copper ions onto stabilized-sludge was an endothermic reaction which can also be demonstrated by the thermodynamic study with the parameters, $\Delta G^{\circ}, \Delta H^{\circ}$ and $\Delta S^{\circ}$.

6. The adsorption capacity of copper ions onto stabilized-sludge was around $23 \mathrm{mg} / \mathrm{g}$, which was greater than that on many other solid wastes. Therefore, the stabilized-sludge seemed to be a good adsorbent on metal ions removal in aqueous solution.

\section{Acknowledgement}

The authors convey their gratitude to the Ministry of Economic Affairs of the Republic of China (Contract No.: 93-EC17-A-10-S1-0007) for financial supports.

\section{References}

[1] N.L. Nemerow, Industrial Water Pollution: Origins, Characteristics, and Treatment, Addison-Wesley, New York, 1978.

[2] E.T. Thostenson, T.W. Chou, Microwave processing: fundamentals and application, Composites Part A 30 (1999) 1055-1071.

[3] J.A. Menendez, M. Inguanzo, J.J. Pis, Microwave-induced pyrolysis of sewage sludge, Water Res. 36 (2002) 3261-3264.

[4] A.A.A. Samra, J.S. Morris, S.R. Koirtyohann, Wet ashing of some biological samples in a microwave oven, Anal. Chem. 47 (8) (1975) 1475-1477.

[5] K.J. Lamble, S.J. Hill, Critical review - microwave digestion procedures for environmental materials, Analyst 123 (1998) 103R-133R.

[6] K. Ganzler, A. Salgo, K. Valko, Microwave extraction: a novel sample preparation method for chromatography, J. Chromatogr. 371 (1986) 299-306.

[7] K. Ganzler, I. Szinai, A. Salgo, Effective sample preparation method for extracting biologically active compounds from different matrices by a microwave technique, J. Chromatogr. 520 (1990) 257.

[8] V. Lopez-Avila, R. Young, Microwave-assisted extraction of organic compounds from standard reference soils and sediments, Anal. Chem. 66 (7) (1994) 1097-1106

[9] B. Perez-Cid, I. Lavilla, C. Bendicho, Application of microwave extraction for partitioning of heavy metals in sewage sludge, Anal. Chim. Acta 378 (1999) 201-210.

[10] M. Gonzalez, M. Barnes, Comparison of microwave-assisted extraction and waste extraction test (WET) preparation for inductively coupled plasma spectroscopic analyses of waste samples, Anal. Bioanal. Chem. 374 (2002) 255-261.
[11] Y.K. Huang, J.S. Chang, Y.U. Kwon, S.E. Park, Microwave synthesis of cubic mesoporous silica SBA-16, Microporous Mesoporous Mater. 68 (2004) 21-27.

[12] I. Kubrakova, Microwave-assisted sample preparation and preconcentration for ETAAS, Spectrochim. Acta Part B - At. Spectrosc. 52 (1997) 1469-1481.

[13] S.W. Kingman, N.A. Rowson, Microwave treatment of minerals - a review, Miner. Eng. 11 (11) (1998) 1081-1087.

[14] S.K. Vanttan, B.A. Docols, D.B. Green, Microwave-assisted synthesis of Group $6(\mathrm{Cr}, \mathrm{Mo}, \mathrm{W})$ zerovalent organometallic carbonyl compounds, Organometallics 19 (2000) 2397-2399.

[15] S.E. Park, D.S. Kim, J.S. Chang, W.Y. Kim, Synthesis of MCM-41 using microwave heating with ethylene glycol, Catal. Today 44 (1998) 301-308.

[16] E. Sedhom, L. Dauerman, N. Ibrahim, G. Windgasse, Microwave treatment of hazardous wastes: "fixation" of chromium in soil, J. Microwave Power Electromagn. Energy 27 (2) (1992) 81-86.

[17] Q. Gan, A case study of microwave processing of metal hydroxide sediment sludge from printed circuit board manufacturing wash water, Waste Manage. 20 (2000) 695-701.

[18] C.L. Chen, S.L. Lo, W.H. Kuan, C.H. Hsieh, Stabilization of $\mathrm{Cu}(\mathrm{II})$ in acid extracted industrial sludge using a microwave process, J. Hazard. Mater. B123 (2005) 256-261.

[19] Y.S. Ho, C.T. Huang, H.W. Huang, Equilibrium sorption isotherm for metal ions on tree fern, Process Biochem. 37 (2002) 1421-1430.

[20] Y.S. Ho, G. McKay, The kinetics of sorption of divalent metal ions onto sphagnum moss peat, Water Res. 34 (2000) 735-742.

[21] K.S. Low, C.K. Lee, A.C. Leo, Removal of metals from electroplating wastes using banana pith, Bioresour. Technol. 51 (1995) 227-231.

[22] Y.S. Ho, G. McKay, Sorption of dyes and copper ions onto biosorbents, Process Biochem. 38 (2003) 1047-1061.

[23] K. Periasamy, C. Namasivayam, Removal of copper(II) by adsorption onto peanut hull carbon from water and copper plating industry wastewater, Chemosphere 32 (1996) 769-789.

[24] Y.S. Li, C.C. Liu, C.S. Chiou, Adsorption of $\mathrm{Cr}(\mathrm{III})$ from wastewater by wine processing waste sludge, J. Colloid Interface Sci. 273 (2004) 95-101.

[25] S.C. Pan, C.C. Lin, D.H. Tseng, Reusing sewage sludge as adsorbent for copper removal from wastewater, Resour. Conserv. Recycl. 39 (2003) 79-90.

[26] C. Namasivayam, K. Ranganathan, Removal of Cd(II) from wastewater by adsorption on "waste" Fe(III)/Cr(III) hydroxide, Water Res. 29 (1994) 1737-1744

[27] A. Mohammad, R.A.K. Rao, A. Rais, A. Jameel, L.A.K. Rao, Removal and recovery of heavy metals from electroplating wastewater by using Kyanite as an adsorbent, J. Hazard. Mater. B87 (2001) 127-137.

[28] E. Kiefer, L. Sigg, P. Schosseler, Chemical and spectroscopic characterization of algae surface, Environ. Sci. Technol. 31 (1997) 759-764.

[29] V. Sandroni, C.M.M. Smith, A. Donovan, Microwave digestion of sediment, soil and urban particulate matter for trace metal analysis, Talanta 60 (2003) 715-723.

[30] E.A. Forbes, A.M. Posner, J.P. Quirk, Specific adsorption of divalent $\mathrm{Cd}, \mathrm{Co}, \mathrm{Cu}, \mathrm{Pb}$ and $\mathrm{Zn}$ on goethite, J. Soil Sci. 27 (1976) 154-166.

[31] T.V. Aualitia, W.F. Pickering, The specific sorption of trace amounts of $\mathrm{Cu}, \mathrm{Pb}$ and $\mathrm{Cd}$ by inorganic particulates, Water Air Soil Pollut. 35 (1987) 171-185.

[32] D. Harvey, Modern Analytical Chemistry, McGraw-Hill, ISBN 0-07116953-9.

[33] W.J. Weber, J.C. Morris, Advances in water pollution research: removal of biologically-resistant pollutants from waste water by adsorption, in: Proc. Int. Conf. on Water Pollution Symp., vol. 2, Pergamon Press, Oxford, 1962, pp. 231-266.

[34] S. Lagergen, Zur Theorie der sogenannten adsorption gelöster stoff, Kungliga Svenska Vetenskapasakademiens, Handlingar 24 (1989) $1-39$.

[35] R. Gündoğan, B. Acemioğlu, M.H. Alma, Copper (II) adsorption from aqueous solution by herbaceous peat, J. Colloid Interface Sci. 269 (2004) 303-309. 
[36] Y.S. Ho, G. McKay, Sorption of dyes from aqueous solution by peat, Chem. Eng. J. 70 (1998) 115-124.

[37] H.M.F. Freundlich, über die adsorption in lösungen, Z. Phys. Chem. 57 (1906) 385-470.
[38] I. Langmuir, the constitution and fundamental properties of solid and liquid, J. Am. Chem. Soc. 38 (1916) 2221-2295.

[39] T.M. Aminabhavi, R.S. Munnolli, Sorption and diffusion of aldehydes and ketones into elastomers, Polym. Int. 32 (1993) 61-70. 